\title{
Por que Lula usou o Mensalão como ferramenta de gestão da coalizão $^{1}$
}

\author{
Why did Lula use Mensalão as a coalition \\ management tool
}

\section{Maristela Mendes de Sant'Ana*1}

Palavras-chave: Presidential toolbox;

Governo Lula;

Mensalão;

Institucionalismo; Presidencialismo de coalizão.
Keywords:

Presidential toolbox; Lula government; Mensalão; Institutionalism;

\begin{abstract}
Resumo: Ao assumir a Presidência da República em 2003, Luiz Inácio Lula da Silva montou e geriu sua base de apoio de forma diferente do que já se mostrara eficaz: na distribuição dos ministérios, desconsiderou a proporção da participação das legendas; no pagamento de emendas orçamentárias, priorizou partidos que não a integravam. Além disso, Lula montou a coalizão com maior número de partidos e mais heterogênea até então. As investigações da Comissão Parlamentar Mista de Inquérito dos Correios e o julgamento da Ação Penal 470 evidenciaram que o Mensalão foi usado como ferramenta de governabilidade, em substituição, ao menos parcial, das tradicionais ferramentas do presidencialismo de coalizão. Este artigo explica o porquê desta prática e conclui que, quando Lula assumiu o governo, o PT era um partido híbrido; reunia características policy-seeking e vote-seeking. A parcela voteseeking, conduzida por José Dirceu, viabilizou a vitória de Lula. Todavia, a esquerda do partido, marcadamente policy-seeking, contava com significativa presença no Parlamento, não podendo ser ignorada na distribuição de cargos. O partido que passara por profundas mudanças e adotara práticas comuns às demais legendas para jogar o jogo eleitoral não se portou da mesma forma ao chegar à Presidência da República. Não quis, ou não conseguiu, jogar o jogo da governabilidade com as ferramentas existentes. Para conseguir governar, mas seguir hegemônico e manter a imagem construída em suas origens, incorporou o Mensalão à caixa de ferramentas de gestão da coalizão.
\end{abstract}

\begin{abstract}
Upon taking office in 2003, Luiz Inácio da Silva set up and managed his coalition in a different way of the one that was already recognized as efficient: in distribution of the cabinet posts, he ignored the proportion of the parties; in payment of budget amendments (pork barrel), he prioritized parties out of
\end{abstract}

\footnotetext{
${ }^{1}$ Recebido em 20/09/2019. Aceito em 27/01/2020

$*^{1}$ Mestre em Ciência Política - Poder Legislativo. E-mail: marissantana1966@gmail.com.
} 
Coalitional presidential system. the coalition. Besides, Lula set up a coalition with the highest number of parties and the most heterogeneous until then. The investigations made by the Joint Parliamentary Committee of Inquiry and the Criminal Action 470 revealed that Mensalão had been used as a governance tool in substitution, at least partially, of the traditional presidential tools. This article explains the reason of this practice and concludes that, when Lula took office, the Workers' Party (PT) was a hybrid party; when Lula took office, the Workers' Party (PT) was a hybrid party; it gathered policy-seeking and vote-seeking characteristics. The voteseeking portion, led by José Dirceu, enabled Lula's victory. However, the party left wing, markedly policy-seeking, had a significant presence in Parliament, what meant it couldn't be ignored in posts distribution. The party that had gone through profound changes and had adopted usual practices of the other parties to play the electoral game didn't act in the same way when it arrived at Brazil's Presidency. The party didn't want, or it was not able, to play the governance game with the existent tools. In order to govern while continuing hegemonic and maintaining the image built in its origins, PT added Mensalão to the presidential toolbox.

\section{Introdução}

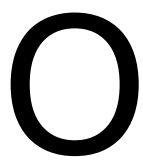

escândalo desvelado em 2005 pelo então deputado Roberto Jefferson, e que ficou conhecido como Mensalão, tem sido estudado por cientistas políticos e juristas, dado seu impacto na política brasileira e o caráter único do julgamento da Ação Penal (AP) 470 pelo Supremo Tribunal Federal (STF).

No campo da Ciência Política, a referência ao Mensalão como integrante do conjunto de ferramentas de gestão da coalizão compõe os estudos de Raile, Pereira e Power (2006) sobre o que denominam presidential toolbox. Este artigo baseia-se em pesquisa de mestrado cuja principal pergunta foi: por que o governo Lula substituiu, ao menos em parte, as tradicionais ferramentas de gestão da coalizão pela remuneração de parlamentares e de partidos políticos o que ficou conhecido como Mensalão?

Essa pergunta traz embutidas duas premissas: o Mensalão existiu e foi utilizado como ferramenta de gestão da coalizão. Os fundamentos para tanto foram buscados em duas fontes documentais: o relatório final da Comissão Parlamentar Mista de Inquérito (CPMI) dos Correios, conhecida como CPMI do Mensalão, e documentos da AP 470. Ambas instâncias confirmaram a prática e suas motivações, que vão além de viabilizar a governabilidade no primeiro governo Lula. Entretanto, o estudo limitou-se às evidências acerca do emprego do Mensalão como ferramenta de gestão da coalizão.

Caderno Eletrônico de Ciências Sociais, Vitória, v. 8, n. 1, pp. 108-135, 2020. 
A pesquisa não ignorou a possibilidade de governos anteriores haverem adotado práticas ilícitas como o Mensalão. O caso mais notório em que se fala da adoção de prática que, em parte, se assemelharia ao Mensalão relaciona-se à denúncia de compra de votos para aprovação da Emenda Constitucional 16/1997, que permitiu a reeleição dos titulares dos Poderes Executivos. Ocorre que, diante da não-comprovação deste e da inexistência de relatos devidamente certificados de práticas semelhantes ao Mensalão - ou seja, de compra de apoio parlamentar como estratégia de governabilidade -, entendeu-se ser possível tratá-lo como caso singular.

Desenvolvida como Estudo de Caso, a pesquisa valeu-se, além da análise documental, de entrevistas gravadas com seis agentes políticos que participaram do governo Lula - os, hoje, ex-deputados federais Chico Alencar (PSOL) e Miro Teixeira (REDE), os deputados federais Patrus Ananias (PT) e Nelson Pellegrino (PT), o ex-senador Eduardo Suplicy (PT) e a ex-senadora Heloísa Helena (Rede) -, além do, hoje, ex-deputado Osmar Serraglio, relator da CPMI dos Correios, na época integrante do PMDB e hoje do PP - cerca de sete horas de depoimentos, cuja transcrição encontra-se nos apêndices da dissertação. $^{2}$

O principal critério para escolha dos entrevistados ligados ao governo foi a relação histórica destes com o Partido dos Trabalhadores (PT); a única exceção foi o deputado Miro Teixeira, que integrou a legenda por curto espaço de tempo, mas foi ministro das Comunicações em 2003 e líder do governo Lula na Câmara dos Deputados em 2004. Soma-se à isso o fato de Teixeira haver integrado a Casa de maneira quase ininterrupta entre 1971 e 2019, o que o credencia como profundo entendedor do sistema político brasileiro.

\footnotetext{
${ }^{2}$ Para a defesa, optou-se pela apresentação de trechos das entrevistas em sete pequenos vídeos. A edição foi realizada de modo a possibilitar visão resumida de pontos relevantes, enfatizando-se as diferentes opiniões sobre o tema em questão pelos entrevistados. Sugere-se aos interessados nos vídeos assisti-los na seguinte ordem. 1 - Mudanças no PT a partir de 1995;

https://www.youtube.com/watch?v=qKekLCYuxEs\&feature=youtu.be 2 - Formação da base de apoio;

https://www.youtube.com/watch?v=d6B519aKIV4\&feature=youtu.be 3 - PT dividido - reflexos na gestão da base de apoio; https://www.youtube.com/watch?v=P6IdV3NU66U\&feature=youtu.be 4 - Responsabilidade pela gestão;

https://www.youtube.com/watch?v=nbBiCmgfnI0\&feature=youtu.be 5- Concentração de cargos no PT;

https://www.youtube.com/watch?v=fuK30A4OH_k\&feature=youtu.be 6 - Crescimento dos partidos da base, mas não do PT; https://www.youtube.com/watch?v=yUszbz6FQUI\&feature=youtu.be 7 - Mensalão como ferramenta de gestão.

https://www.youtube. com/watch?v=nFHG1aDtXiw\&feature=youtu.be
}

Caderno Eletrônico de Ciências Sociais, Vitória, v. 8, n. 1, pp. 108-135, 2020. 
Os entrevistados com vínculos históricos com o PT abrangem dois grupos: os que saíram do partido - Chico Alencar e Heloísa Helena - e os que permanecem na legenda - Patrus Ananias, Nelson Pellegrino e Eduardo Suplicy, o que permitiu a obtenção de visões e explicações diferentes para o fenômeno.

O critério para definição do perfil dos entrevistados justifica-se por valerse a pesquisa do Institucionalismo Histórico como base teórica para responder sua principal pergunta, e da Teoria da Escolha Racional para entender o processo de mudanças realizadas pelo PT entre 1995 e 2002, visando à eleição de sua maior liderança para o cargo de presidente da República. Convém ressaltar que o Institucionalismo Histórico é usado por Hunter (2010) na análise do fenômeno do Mensalão. O estudo realizado busca agregar a essa linha de pesquisa os depoimentos dos personagens entrevistados.

Inicialmente, este artigo aborda o sucesso na gestão da coalizão montada por Lula, bem como o porquê de o Mensalão poder ser entendido como ferramenta de gestão da coalizão e, como tal, integrante da chamada presidential toolbox. Em seguida, é apresentado um brevíssimo resumo da história do PT, tendo como enfoques principais sua origem, valores e mudanças realizadas a partir de 1995, objetivando chegar à Presidência da República. A terceira parte trata da formação do primeiro governo Lula e como a gestão de sua base de apoio ocorreu de forma diferente do praticado até então. Em seguida, abordam-se especificamente as características do PT ao chegar ao Planalto e como estas impactaram a gestão da base do governo. Por fim, a conclusão apresenta como, apesar de todas as mudanças realizadas para chegar ao Planalto, a trajetória do PT influenciou significativamente a forma como Lula montou e geriu sua coalizão e, consequentemente, a incorporação do Mensalão à presidential toolbox.

\section{Neo-Institucionalismo e suas vertentes}

Três métodos de análise surgidos na década de 1980 são agrupadas sob o título de Neo-Institucionalismo: Institucionalismo Histórico (IH), Institucionalismo da Escolha Racional (IER) e Institucionalismo Sociológico (IS). A análise institucional se preocupa com o impacto das instituições no comportamento dos indivíduos. Segundo Hall e Taylor (2003), de modo geral, os neo-institucionalistas fornecem dois tipos de abordagem a essa reflexão, "que poderíamos designar como a 'perspectiva calculadora' e a 'perspectiva cultural'. Cada uma delas responde de modo ligeiramente diferente a três questões básicas: "como os atores se comportam?"; "o que fazem as instituições?"; "por que as instituições se mantêm?" (HALL; TAYLOR, 2003, p.197).

Caderno Eletrônico de Ciências Sociais, Vitória, v. 8, n. 1, pp. 108-135, 2020. 
Para os partidários da perspectiva "calculadora", os indivíduos (atores) adotam um comportamento estratégico voltado à maximização dos resultados. Tal forma de agir é viabilizada pela perspectiva da relativa certeza, trazida pelas instituições, do comportamento presente e futuro dos demais atores. Já sob a ótica da perspectiva cultural, esse comportamento jamais é inteiramente estratégico - racional e orientado para fins determinados. Ela "enfatiza o fato de que os indivíduos recorrem com frequência a protocolos estabelecidos ou a modelos de comportamento já conhecidos para atingir seus objetivos". (HALL; TAYLOR, 2003, p.197).

Os adeptos do Institucionalismo Histórico, apesar de reconhecerem o papel das instituições na vida política, não as veem como único fator que as influencia; recorrem tanto à perspectiva calculadora quanto à cultural quando analisam a relação entre as instituições e as ações dos indivíduos. Os adeptos do Institucionalismo Histórico rejeitam o postulado tradicional de que as mesmas forças ativas produzem, em todo lugar, os mesmos resultados. Eles defendem que as forças ativas são modificadas pelas propriedades do contexto local, herdadas do passado (path dependent). O conceito de path dependency aplicado a países, sociedades e sistemas baseia-se na premissa de que eventos passados influenciam a situação presente. Assim, uma vez adotada uma trilha, feita uma escolha inicial, os custos para revertê-la são muito altos.

A corrente denominada Escolha Racional tem como premissa básica que as instituições são compostas por atores individuais que tomam decisões e agem a partir de escolhas e interesses pessoais.

Segundo Hall e Taylor (2003), as análises feitas por adeptos do Institucionalismo da Escolha Racional reúnem quatro propriedades resumidas a seguir:

1) os atores compartilham um conjunto de preferências e se comportam estrategicamente, de modo a maximizar a satisfação destas;

2) a vida política é uma série de dilemas de ação coletiva - situações em que os indivíduos agem para maximizar a satisfação de suas preferências com o risco de produzir um resultado subótimo para a coletividade;

3) em determinadas situações políticas, o comportamento de um ator é influenciado por um cálculo estratégico que considera as prováveis reações dos demais, cuja incerteza é reduzida pela interação promovida pelas instituições; e

4) o processo de criação das instituições está geralmente centrado em um acordo voluntário entre os atores interessados e baseia-se no benefício que estas Ihes podem propiciar.

O Institucionalismo Sociológico surge, no fim dos anos 1970, da contestação da distinção tradicional entre o mundo social e o mundo cultural. Para os adeptos

Caderno Eletrônico de Ciências Sociais, Vitória, v. 8, n. 1, pp. 108-135, 2020. 
desta escola, tanto as formas e procedimentos das instituições modernas quanto as práticas aparentemente mais burocráticas não se devem simplesmente à busca da eficácia (racionalidade), mas também as práticas culturais.

\section{Sucesso na gestão da coalizão}

Em seu primeiro mandato como presidente da República, Luiz Inácio Lula da Silva montou e geriu sua coalizão de governo de forma diferente da prática que, até então, mostrava-se bem-sucedida. De maneira geral, os presidentes que $o$ antecederam buscavam constituir bases de apoio pouco heterogêneas e valiam-se, basicamente, de duas ferramentas como forma de garantir governabilidade: distribuição do ministério entre os partidos aliados, respeitada a proporcionalidade de sua participação - a chamada coalescência - e pagamento de emendas orçamentárias - prioritariamente para parlamentares aliados, e subsidiariamente para membros de partidos que, mesmo não integrando o governo, o apoiavam em votações específicas, na maioria das vezes em troca da liberação de emendas.

Power (2011) destaca que o estudo por ele elaborado com Carlos Pereira e Eric Raile defende que coalizões superdimensionadas, com elevada heterogeneidade ideológica e alta concentração interna de poder (em detrimento de outros membros da coalizão) são especialmente difíceis de administrar. Segundo estes autores, Fernando Henrique Cardoso e Luiz Inácio Lula da Silva gerenciaram suas coalizões de apoio por meio do ajuste contínuo de três variáveis relacionadas à coalizão parlamentar - tamanho, heterogeneidade e proporcionalidade, - associado ao uso de recursos orçamentários (gastos clientelistas).

\footnotetext{
Essas ferramentas, até agora, têm sido tratadas separadamente na literatura, mas Raile, Pereira e Power as combinam numa perspectiva analítica integrada - a "caixa de ferramentas do Executivo" - a qual propõem como uma protoabordagem para a análise da governabilidade no presidencialismo multipartidário (POWER, 2011, p. 138).
}

Raile, Pereira e Power (2006) apresentam, no artigo The Presidential Toolbox: Generating Support in a Multiparty Presidential Regime, a tabela denominada Strategic Profiles for Executives, parcialmente reproduzida a seguir no Quadro 1, na qual dispõem, de forma comparativa, como FHC e Lula utilizaram as ferramentas de gestão da coalizão. A comparação entre os dois presidentes é válida pelo fato de, no período democrático compreendido entre a promulgação da Constituição de 1988 até o fim do primeiro governo Lula, este e

Caderno Eletrônico de Ciências Sociais, Vitória, v. 8, n. 1, pp. 108-135, 2020. 
Fernando Henrique Cardoso haverem sido os únicos presidentes eleitos pelo voto direto que cumpriram integralmente o mandato.

Quadro 1 - Principais características dos governos ${ }^{3}$

\begin{tabular}{|c|c|c|}
\hline & Cardoso & Lula \\
\hline $\begin{array}{l}\text { Heterogeneidade } \\
\text { gabinete }\end{array}$ & $\begin{array}{l}\text { Menor na média do que } \\
\text { a de Lula; decrescente } \\
\text { ao longo do tempo }\end{array}$ & $\begin{array}{l}\text { Maior na média que a de } \\
\text { Cardoso; crescente ao } \\
\text { longo do tempo }\end{array}$ \\
\hline $\begin{array}{l}\text { Número efetivo } \\
\text { partidos na coalizão }\end{array}$ & $\begin{array}{l}\text { Mais baixo na média; } \\
\text { decrescente ao longo do } \\
\text { tempo }\end{array}$ & $\begin{array}{l}\text { Mais alto na média; } \\
\text { crescente ao longo do } \\
\text { tempo }\end{array}$ \\
\hline Coalescência do gabinete & $\begin{array}{l}\text { Mais alta na média; } \\
\text { decrescente ao longo do } \\
\text { tempo }\end{array}$ & $\begin{array}{l}\text { Mais baixa na média; } \\
\text { decrescente ao longo do } \\
\text { tempo }\end{array}$ \\
\hline o de emendas & $\begin{array}{l}\text { Mais alto na média; } \\
\text { crescente ao longo do } \\
\text { tempo }\end{array}$ & $\begin{array}{l}\text { Mais baixo na média; } \\
\text { crescente ao longo do } \\
\text { tempo }\end{array}$ \\
\hline $\begin{array}{l}\text { Proporção gasta com a } \\
\text { coalizão }\end{array}$ & $\begin{array}{l}\text { Mais alta na média; } \\
\text { crescente ao longo do } \\
\text { tempo }\end{array}$ & $\begin{array}{l}\text { Mais baixo na média; } \\
\text { crescente } \\
\text { significativamente } \\
\text { longo do tempo }\end{array}$ \\
\hline ncial & $\begin{array}{l}\text { Correlação negativa forte } \\
\text { com o pagamento de } \\
\text { emendas }(-0,882)\end{array}$ & $\begin{array}{l}\text { Correlação negativa } \\
\text { moderada com o } \\
\text { pagamento de emendas } \\
(-0,458)\end{array}$ \\
\hline
\end{tabular}

Fonte: A autora, 2019.

Em média, conforme sintetizado no quadro acima, os gabinetes de Lula foram mais heterogêneos e reuniram maior número de partidos do que os de FHC, ao passo que este organizou ministérios com maior grau de coalescência e realizou maiores gastos com pagamento de emendas orçamentárias individuais, além de destinar uma parcela maior desses recursos para membros da coalizão.

Ao longo do tempo, ambos os governos, de maneira geral, incrementaram os gastos com emendas e reduziram o grau de coalescência do gabinete. Mas FHC reduziu a heterogeneidade do gabinete e o número de partidos integrantes da coalizão, enquanto Lula adotou estratégia oposta: aumentou o número de partidos e o grau de heterogeneidade da coligação, além de ampliar significativamente a parcela de gastos orçamentários com membros de partidos da coalizão.

Pereira, Power e Raile (2009) destacam que Lula usou a composição do gabinete (heterogêneo e com grande número de partidos) como complemento dos gastos orçamentários, enquanto FHC usou tais ferramentas de forma

\footnotetext{
${ }^{3}$ Fonte: Adaptado da tabela denominada Strategic Profiles for Executives, apresentada por Raile, Pereira e Power (2006, p.33, tradução nossa).
} 
oposta. Ainda em relação às emendas orçamentárias, Lula aumentou substancialmente o uso dessa ferramenta para a própria coalizão, com ênfase para os membros ideologicamente mais distantes, que tinham pouca participação no gabinete, destinando uma proporção muito menor para o seu partido, o PT. Tanto no caso de Lula quanto FHC, as mudanças na popularidade do presidente apresentaram correlação negativa com os gastos com emendas.

\begin{abstract}
Essas medidas corretivas e o sucesso legislativo de Lula no primeiro ano de mandato não foram considerados o suficiente. Lula havia aprendido que administrar as facções internas do PT seria extremamente difícil. Também havia aprendido que lidar com a oposição sairia caro: a obtenção dos votos do PSDB e do PFL para as reformas constitucionais havia sido bastante cara apesar da satisfação ideológica desses partidos com as medidas legislativas. Outra lição importante foi que o apoio do público em geral podia ser um pouco volúvel uma vez que a lua de mel acabou rapidamente devido as insatisfações com relação às reformas constitucionais e a erosão natural do apoio. 4A lição mais importante para Lula pode ter sido que ele estava lidando basicamente com partidos políticos de fraca ideologia, oportunistas e clientelistas - um contexto que historicamente havia se prestado a uma forma extrema de "política de trocas" (Geddes; Riberito Neto, 1999). A fome por bens individualizados é uma constante na política brasileira e Lula enfrentou expectativas de que transferências de recursos seriam necessárias para conseguir qualquer coisa naquele sistema político fragmentado (PEREIRA; POWER; RAILE, 2009, p. 225).
\end{abstract}

Ao assumir o governo em 2003, Lula formou uma base pulverizada, heterogênea, com partidos variando em um amplo espectro ideológico. O novo ministério foi integrado de forma majoritária pelo PT, em prejuízo dos demais partidos que a integravam.

Conforme análise elaborada por Pereira, Power e Raile (2009), tal perfil ministerial se manteve mesmo após o ingresso do então PMDB - hoje MDB - na coalizão presidencial, em 2004, quando esta atingiu 318 parlamentares. Destes, $91(28,62 \%)$ eram do PT, $78(24,53 \%)$ do PMDB e $9(2,83 \%)$ do PCdoB. No entanto, o PT detinha a titularidade de 21 dos 35 cargos no gabinete $(60 \%)$ ministérios e secretarias com status ministerial -, ao passo que o PMDB, o mesmo número do PCdoB, a saber, duas pastas cada uma das legendas, o equivalente a $5,71 \%$ das 35 existentes. Os demais partidos que compunham a base (PPS, PTB, PL, PSB e PV) e que reuniam 140 deputados (44,03\% desta)

\footnotetext{
${ }^{4}$ Segundo a Pesquisa de Opinião Pública Nacional - Rodada 67 - CNT/Sensus, realizada entre 4 e 6 de fevereiro de 2004, a avaliação positiva do presidente Lula era de 39,9\%, a regular, $40,6 \%$ e a negativa, 15,1\%. A título de comparação, a Rodada 59, realizada entre 19 e 23 de janeiro de 2003, apontava, respectivamente, $56,6 \%, 17,7 \%$ e $2,3 \%$.
}

Caderno Eletrônico de Ciências Sociais, Vitória, v. 8, n. 1, pp. 108-135, 2020. 
respondiam por $14,29 \%$ do gabinete. Cinco pastas (14,29\%) eram ocupadas por titulares qualificados como independentes.

Ainda segundo os autores, a base de apoio de Fernando Henrique Cardoso quando este montou o segundo gabinete de seu primeiro mandato reuniu 381 deputados federais. Destes, 99 (25,98\%) eram do PSDB, $105(27,56 \%)$ do então PFL e $83(21,78 \%)$ do PMDB. A participação destes na distribuição do ministério era, respectivamente: $28,57 \% ; 19,05 \%$ e $9,52 \%$. Os demais partidos da base (PP, PPS e PTB) somavam 94 (24,67\% da base) e ocupavam 4 ministérios $(19,05 \%)$. Também nesse gabinete, 5 pastas $(23,81 \%)$ eram ocupadas por independentes. O quadro 2 apresenta, de forma mais detalhada, esses números.

Quadro 2: Representação dos partidos integrantes da coalizão

\begin{tabular}{|c|c|c|c|c|c|c|c|c|}
\hline Partido & \multicolumn{4}{|c|}{ Fernando Henrique Cardoso ${ }^{5}$} & \multicolumn{4}{|c|}{ Luiz Inácio Lula da Silva ${ }^{6}$} \\
\hline & $\begin{array}{l}\text { Cargos } \\
\text { no } \\
\text { Gabi- } \\
\text { nete }\end{array}$ & $\begin{array}{l}\text { \% de } \\
\text { cargos }\end{array}$ & $\begin{array}{l}\text { Membros } \\
\text { da } \\
\text { coalizão } \\
\text { na } \\
\text { Câmara }\end{array}$ & $\begin{array}{l}\text { \% de } \\
\text { repre- } \\
\text { sentação } \\
\text { da } \\
\text { Câmara }\end{array}$ & $\begin{array}{l}\text { Cargos } \\
\text { no } \\
\text { Gabi- } \\
\text { nete }\end{array}$ & $\begin{array}{lr}\% & \text { de } \\
\text { cargos }\end{array}$ & $\begin{array}{l}\text { Membros } \\
\text { da } \\
\text { coalizão } \\
\text { na } \\
\text { Câmara }\end{array}$ & $\begin{array}{l}\% \text { de } \\
\text { repre- } \\
\text { sentação } \\
\text { da } \\
\text { Câmara }\end{array}$ \\
\hline PSDB & 6 & 28,57 & 99 & 25,98 & & & & \\
\hline PFL & 4 & 19,05 & 105 & 27,56 & & & & \\
\hline PMDB & 2 & 9,52 & 83 & 21,78 & 2 & 5,71 & 78 & 24,53 \\
\hline PP & 2 & 9,52 & 60 & 15,75 & & & & \\
\hline PPS & 1 & 4,76 & 3 & 0,79 & 1 & 2,86 & 20 & 6,29 \\
\hline PTB & 1 & 4,76 & 31 & 8,14 & 1 & 2,86 & 51 & 16,04 \\
\hline PT & & & & & 21 & 60,00 & 91 & 28,62 \\
\hline PCdoB & & & & & 2 & 5,71 & 9 & 2,83 \\
\hline $\mathrm{PL}$ & & & & & 1 & 2,86 & 43 & 13,52 \\
\hline PSB & & & & & 1 & 2,86 & 20 & 6,29 \\
\hline PV & & & & & 1 & 2,86 & 6 & 1,89 \\
\hline Ind. & 5 & 23,81 & & & 5 & 14,29 & & \\
\hline Totais & 21 & 100,00 & 381 & 74,27 & 35 & 100,00 & 318 & 61,99 \\
\hline
\end{tabular}

Fonte: Adaptado de Pereira, Power e Raile, 2009, p.217.

Para efeito de comparação, pode-se considerar o índice chamado cabinet disparity, apresentado por Melo e Pereira (2013). A medida resulta da diferença entre a porcentagem de cargos no gabinete presidencial (ministérios e secretarias com status assemelhado) ocupados pelos partidos integrantes da base do governo e a porcentagem destes nesta base, consideradas as bancadas na Câmara dos Deputados. Valores negativos indicam que o partido recebeu uma porcentagem desproporcionalmente baixa de cargos ministeriais, ao passo que valores positivos revelam percentual desproporcionalmente alto de postos no gabinete. Segundo os autores, o cabinet disparity de Lula no período acima

\footnotetext{
${ }^{5}$ Segundo gabinete do segundo mandato.

${ }^{6}$ Segundo gabinete do primeiro mandato.
}

Caderno Eletrônico de Ciências Sociais, Vitória, v. 8, n. 1, pp. 108-135, 2020. 
era positivo para o PT e PCdoB (31,38 e 2,88 - respectivamente) e negativo para o PMDB $(-18,82)$. Em relação a $\mathrm{FHC}$, o índice apurado foi positivo para o PSDB $(2,59)$; e negativo para as outras duas legendas: PFL $(-8,51)$ e PMDB ($12,26)$.

Esses percentuais e índices evidenciam que, apesar de, em ambos gabinetes, a participação do partido do presidente da República no ministério ser maior do que proporção da legenda na base de apoio do governo, a parcela de cargos destinada ao Partido dos Trabalhadores era significativamente maior do que, considerado o critério da coalescência, Ihe seria "devido".

Chama a atenção também a estratégia de execução das emendas orçamentárias.

Do valor total, $75,70 \%$ de pork foram para indivíduos de partidos fora da coalizão em 2003 e 40,63\% para partidos centrais de oposição (PSDB e PFL). A quantia foi ainda maior no caso das emendas coletivas estaduais, com $89,43 \%$ desembolsados para estados liderados por partidos fora da coalizão (e 33,56\% do total geral para estados controlados pelo PSDB e PFL) (PEREIRA, POWER e RAILE, 2009, p. 223).

Quanto ao pagamento de emendas, os gastos de Fernando Henrique Cardoso privilegiavam os integrantes da sua coalizão.

Ao cabo, contudo, pode-se afirmar que Lula conseguiu resolver a chamada "equação da governabilidade", na medida em que obteve sucesso legislativo semelhante a Fernando Henrique Cardoso. Ao analisar as votações nominais do período 1988-2007, Figueiredo e Limongi (2007) ressaltam que o percentual de derrotas em proposições que dependiam de quórum simples para aprovação experimentadas por Lula em seu primeiro mandato assemelha-se ao registrado por $\mathrm{FHC}$ em seus oito anos de governo - respectivamente oito em 134 votações $(5,97 \%)$ e onze em 205 (5,37\%).

\section{Mensalão como presidential tool}

Tanto a investigação política quanto a jurídica do Mensalão concluíram que os recursos do chamado Mensalão eram utilizados para dois fins específicos: aumentar a base de apoio no Congresso Nacional por meio do ingresso de parlamentares em partidos que a integravam, e garantir votos na aprovação de matérias de interesse do governo. Tais constatações foram possíveis a partir do cotejamento do fluxo de recursos do chamado "Valerioduto"7 com dois eventos: migração de parlamentares para partidos da

\footnotetext{
7 Como ficou conhecido o conjunto de contas bancárias pertencentes ao publicitário Marcos Valério Fernandes de Souza, por meio das quais circulavam os recursos do Mensalão.
}

Caderno Eletrônico de Ciências Sociais, Vitória, v. 8, n. 1, pp. 108-135, 2020. 
base e votação de propostas como a Reforma da Previdência e a Reforma Tributária. Diagramas elaborados pela CPMI (SENADO FEDERAL, 2006) evidenciam correlação direta entre os fatores, além de revelarem transferências de recursos já em janeiro de 2003, o que põe em dúvida o entendimento existente de que o Mensalão ter-se-ia iniciado, ao final do primeiro ano do governo, após dificuldade de aprovação das citadas reformas. Ou seja, os recursos do chamado Mensalão eram usados com os mesmos objetivos das tradicionais ferramentas de gestão da coalizão, o que permite dizer que integrou a chamada presidential toolbox. O diagrama a seguir ilustra a referida correlação especificamente em relação ao PTB. 
Figura 1: Diagrama do Partido Trabalhista Brasileiro (PTB)

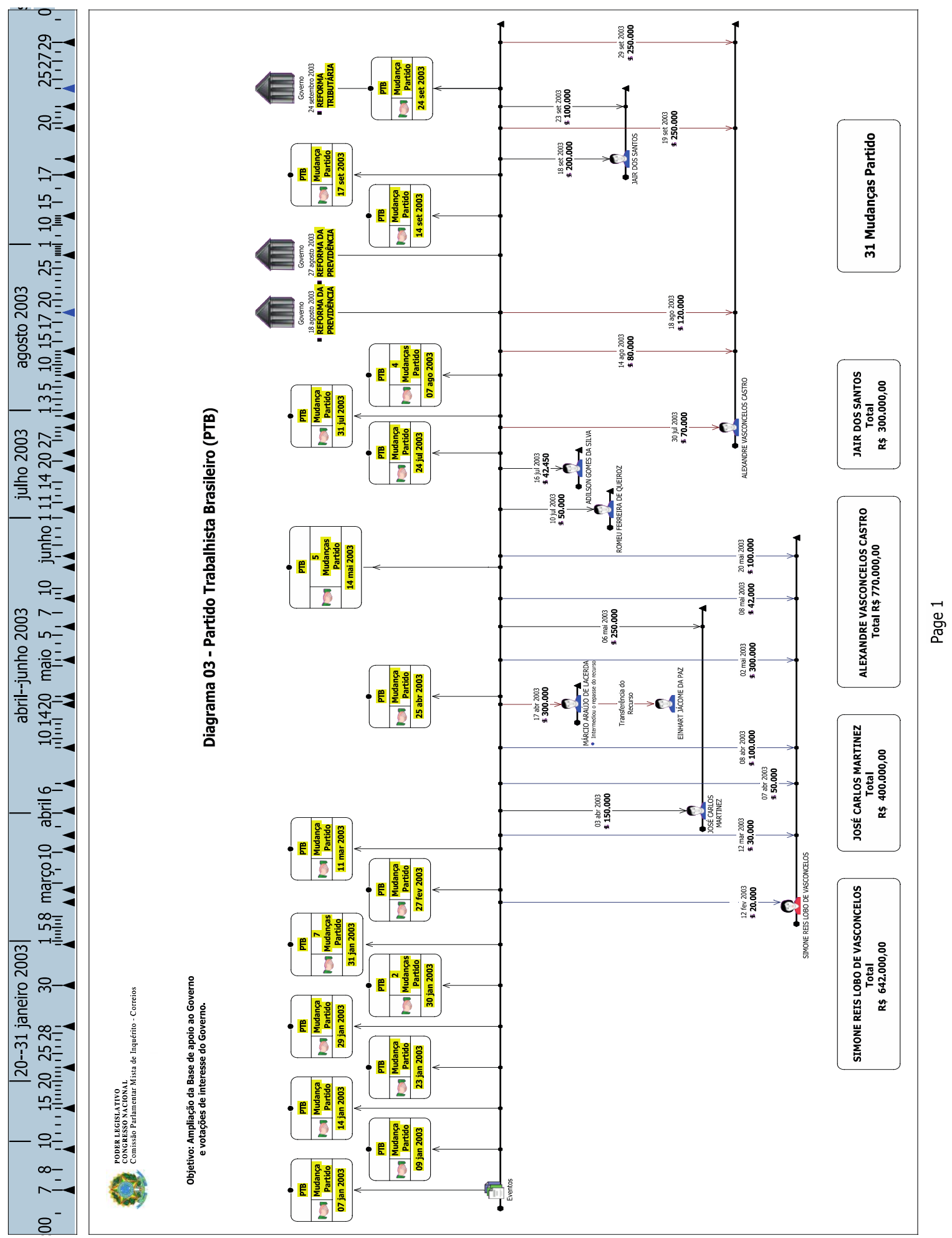

Fonte: Sítio do Senado Federal, 2006.

Caderno Eletrônico de Ciências Sociais, Vitória, v. 8, n. 1, pp. 108-135, 2020. 
Ao analisar o desempenho do governo Lula no Parlamento, Figueiredo e Limongi (2007), ressaltam: "Suas qualidades pessoais como negociador, que saibamos, não foram ressaltadas. Ou seja, o que se chama de virtude política não passa do reconhecimento de que é necessário contar com o apoio de maioria ancorada em bases partidárias para governar (FIGUEIREDO; LIMONGI, 2007, p. 30). Os estudos de Pereira, Power e Raile (2009), por sua vez evidenciaram a subutilização por Lula dos instrumentos habitualmente utilizados na formação e gestão dessa base. Pode-se, portanto, inferir haver sido o Mensalão empregado de forma suplementar a estes.

A pergunta que resta é: por quê? Por que o governo Lula substituiu, ao menos em parte, as tradicionais ferramentas de gestão da coalizão pela remuneração de parlamentares e de partidos políticos - o que ficou conhecido como Mensalão?

A resposta para essa pergunta foi buscada na trajetória do PT. A seção a seguir apresenta aspectos dessa história considerados mais relevantes para o estudo realizado.

\section{Um pouco sobre a história do Partido dos Trabalhadores}

A trajetória do Partido dos Trabalhadores pode ser dividida em quatro momentos, marcados por fatos significativos na trajetória da legenda e em princípios que a regiam. O primeiro vai da sua fundação, em 1980, até o final de 1994 quando, após perder pela segunda vez a disputa para a Presidência da República, Luiz Inácio Lula da Silva decide não participar de novo pleito, salvo se fosse "dono de sua campanha". O segundo, do início do processo de mudança iniciado em 1995 até 2002, com a eleição de Lula para a Presidência da República. O terceiro, de 2003 - quando o partido assume o protagonismo do cenário político nacional - a maio de 2016, com o afastamento de Dilma Rousseff do Palácio do Planalto e o retorno do PT à oposição. Quanto ao quarto momento, pode-se entender que este ainda vige, sendo marcado pela prisão de Lula em abril de 2018, a ausência do ex-presidente no pleito de 2018 e a derrota de Fernando Haddad para Jair Bolsonaro (PSL).

Uma vez que a pesquisa realizada teve como foco o primeiro governo Lula, os períodos subsequentes não foram objeto de estudo. Da mesma forma, da história do PT até 2002, atenção especial foi dedicada à sua origem e ao processo de mudança do partido, dada sua relevância para o entendimento das características da legenda ao chegar ao poder e o impacto destas na forma como o governo geriu sua coalizão de apoio.

Caderno Eletrônico de Ciências Sociais, Vitória, v. 8, n. 1, pp. 108-135, 2020. 
No começo, caracterizava o PT como um partido externally mobilized e policy-seeking. ${ }^{8}$

De fato o PT começa como uma força muito novidadeira na política brasileira, talvez o único partido dos atuais, dos que existem, que tenha nascido do chão da fábrica, dos movimentos populares, das comunidades eclesiais de base, de fora para dentro dos palácios, não por trás das cortinas, por dissidências internas de partidos. Ele tem uma gênese muito virtuosa, do ponto de vista de um partido vinculado às lutas sociais, ao crescimento da consciência política dos trabalhadores de uma maneira geral (ALENCAR, 2017, em entrevista à autora).

Sua origem, ainda quando o Brasil vivia os estertores da ditadura civilmilitar e o mundo dava início à última década da guerra fria, aliada à pluralidade dos grupos que o integraram, contribuiu para que o PT se identificasse como um partido de esquerda composto por várias tendências cujos embates o marcaram internamente. Para Martins (2016), o PT ter "inventado sua própria direita" foi a forma encontrada para continuar decifrando a política no marco obsoleto da Guerra Fria; "definiu como 'de direita' todos os partidos e todas as pessoas que não estivessem alinhados com o petismo. Autoproclamou-se 'a esquerda" sem sê-lo" (MARTINS, 2016, p.12).

"O PT [...] mesmo sem ter uma definição ideológica clara, foi uma agremiação mais radical do que os partidos comunistas que, em sua época, evidentemente já existiam. Ao final, eles acabaram por se tornar satélites do PT" (SECCO, 2011, p. 258). Somente eram admitidas alianças com legendas de esquerda e, dado seu rápido crescimento no cenário político, o PT não abria mão da liderança das chapas que integrava. Outra marcante característica era a rejeição ao financiamento empresarial de campanhas eleitorais, por recear que impedisse a implantação das políticas públicas defendidas pela legenda.

$\mathrm{Na}$ formação do PT, juntaram-se aos sindicalistas outros grupos. Vieira (2012) elenca como representativos componentes na formação do PT: as lideranças do novo sindicalismo, encabeçada por Lula; políticos do MDB paulista marginalizados pelas lideranças de seu partido após as eleições de 1978; intelectuais; organizações de esquerda, apesar da pouca afinidade ideológica

\footnotetext{
8 "Partidos externally mobilized são criados por líderes que não ocupam posições de poder no regime dominante e buscam abrir caminho no sistema político por meio da mobilização e organização de uma massa eleitoral" Martin Shefter (1994, apud HUNTER, 2007, p.446, tradução nossa). Hunter (2007) acresce que, na maioria das vezes, tais lideranças orientam suas energias para a construção de organizações de longo prazo, ao invés da maximização do número de votos. Suas origens externally mobilized irão moldar sua futura orientação e organização, motivando-os pela busca ideológica de um elenco de políticas públicas (policyseeking).
}

Caderno Eletrônico de Ciências Sociais, Vitória, v. 8, n. 1, pp. 108-135, 2020. 
entre elas; e movimentos populares urbanos, em boa parte liderados por setores progressistas da Igreja Católica.

Nove anos após a fundação, a derrota para Fernando Collor de Mello em 1989 levou o PT - em uma tentativa de reprodução do shadow cabinet britânico - à criação, em 1990, do Governo Paralelo, três anos depois transformado no Instituto Cidadania, voltado para estudos técnicos e de reconhecimento do território nacional. "Era a forma dentro da qual as novas contradições (agora entre o PT e o mundo externo) encontravam para se movimentar. Começava aí uma verdadeira autonomização de Lula e seu círculo próximo em relação ao PT". (SECCO, 2011, p. 163).

Em 1994, a primeira derrota para FHC e a ameaça de Lula de não mais concorrer caso não fosse dono da própria campanha marcam o início do processo de mudanças no partido, aqui identificado como segundo momento. Alencar lembra que, logo após o pleito de 1994, Lula afirmou:

Cansei de rodar bolsinha para o povo brasileiro nas ruas desse país. Agora eu quero força para ganhar eleição e isso significa recursos. Delúbio, toca isso aí e não dá mais para ser só bonitinho e marcador de posição. Tem que entrar para ganhar e se eu puder ter um Duda Mendonça como marqueteiro, eu sei que ele cobra caríssimo, nós vamos ter (ALENCAR, 2017, em entrevista à autora).

A autonomização de Lula citada por Secco (2011) e de outras lideranças petistas se consolidou com a formação, em 1995, do grupo moderado Campo Majoritário, e da chegada de José Dirceu à presidência da legenda. A direção de esquerda perdeu espaço, as estratégias de moderação e ampliação das alianças foram estendidas e o programa do partido tornou-se ainda mais flexível. As mudanças empreendidas no PT sob a liderança de Dirceu incluíram a profissionalização das campanhas eleitorais, não mais baseadas exclusivamente no trabalho da militância; a adoção de financiamento empresarial de campanha; e a realização de coligações para campanhas subnacionais. A legenda assumia, progressivamente, um perfil vote-seeking. ${ }^{9}$

Paralelamente, o partido investiu na suavização da imagem de seu principal líder, então rechaçado por segmentos da sociedade, como: empresários, ruralistas, banqueiros, mulheres e evangélicos. A rejeição a Lula caiu quando se consolidou a imagem do "Lula, paz e amor", criada pelo publicitário Duda Mendonça - o marqueteiro que, segundo Alencar, fora apontado por Lula como preferido. O partido experimentou grande crescimento

\footnotetext{
9 Segundo Amaral (2010), tais organizações visam, antes de tudo, a vencer eleições, valendo-se de campanhas altamente profissionalizadas e de um programa maleável que pode ser mais facilmente alterado para maximizar as possibilidades de vitória eleitoral.
}

Caderno Eletrônico de Ciências Sociais, Vitória, v. 8, n. 1, pp. 108-135, 2020. 
eleitoral nos municípios, mas distanciava-se, progressivamente, da classe trabalhadora e dos movimentos sociais ligados à sua origem.

O partido preocupava-se cada vez menos em defender os interesses dos trabalhadores e cada vez mais em expandir sua ocupação nos cargos públicos. Nas campanhas eleitorais municipais de 1996, o PT tentou passar a imagem de um partido ainda menos combativo. Os slogans utilizados ("O PT faz bem", "O PT é bom de governo" e "onde o PT governa dá certo") remetiam a um partido mais pacífico e conciliador (VIEIRA, 2012, p. 29).

A política de alianças do PT se flexibilizava cada vez mais. Eram defendidas alianças com diversos partidos e personalidades, desde que se opusessem ao neoliberalismo e ao governo de FHC. No IX Encontro Nacional do PT (1994), o partido decidiu, pela primeira vez, aceitar doações de pessoas jurídicas em uma campanha.

O Banco Itaú, surpreendentemente, doou aproximadamente 500 mil reais. [...]. Mais alarmante do que isso foi a doação da empreiteira Odebrecht para a campanha de José Dirceu ao governo do estado de São Paulo. Meses antes, parlamentares do PT haviam acusado a empresa de participar de um esquema de fraude no Orçamento da União (VIEIRA, 2012, p. 27).

Acerca das doações empresariais, cabe avançar um pouco no tempo para citar o relato de Suplicy de que, no primeiro semestre de 2002, Chico Alencar propusera, na reunião do diretório nacional, o registro em tempo real de toda e qualquer contribuição, inclusive das empresas, no site do partido, "mas, naquela ocasião, o tesoureiro Delúbio Soares ponderou: 'olha, se nós formos divulgar quais empresários que estão colaborando, e tudo, isso vai inibir potenciais doadores, e acho melhor que não seja feito'. Olha, se tivéssemos adotado a proposta de Chico Alencar, muitos dos problemas que depois aconteceram teriam sido prevenidos" (SUPLICY, 2018, em entrevista à autora).

De volta ao processo de mudança. Apesar de duradoura, eficaz e conduzida com firmeza, a liderança de José Dirceu não significava, numericamente, grande apoio do partido. Nas várias eleições internas para a presidência do partido, suas vitórias (Campo Majoritário) resultavam de maiorias apertadas. As tendências que compunham a chamada esquerda do partido - por defenderem bandeiras mais radicais -, apesar de contidas, eram significativas. Sobre a parceria entre Lula e José Dirceu, Alencar comenta:

[...] o Lula e o Zé Dirceu, embora tivessem suas visões diferentes, suas estratégias até distintas, eles nunca deixaram de ser aliados. $O$ Zé Dirceu era a expressão do que o Campo Majoritário, vale dizer, Lula, queria para o PT. E eles nunca tiveram divergências. Nós, a

Caderno Eletrônico de Ciências Sociais, Vitória, v. 8, n. 1, pp. 108-135, 2020. 
chamada esquerda do PT, fomos crescendo e conseguimos fazer esses embates internos que levaram o Zé a ter sempre uma maioria pequena para controlar a direção nacional. [...] Então esse Campo Majoritário [...] é também um conjunto de forças que hegemoniza o PT até hoje nessa linha de mais moderação, de conciliação de classes, inclusive de um projeto reformista [...] Agora, o Lula é um sensitivo, pragmático, com alta empatia popular. O Zé Dirceu é cerebral, tem visão estratégica, é um formulador e é um pragmático também. E o partido era controlado por ele (ALENCAR, 2017, em entrevista à autora).

Merece destacar também que as mudanças realizadas não eram discutidas ou confirmadas por suas bases. Segundo Alencar, "foi uma transição não explicitada e debatida. Foi algo silenciosa essa transfiguração do PT para um partido que convive mais com a ordem e não quer tanto alterá-la, revolucioná-la. [...] O PT perdeu esse éthos revolucionário" (ALENCAR, 2017, em entrevista à autora). A forma como se deram as mudanças também é criticada por Helena.

[...] eu acho que todas essas mudanças deveriam ter sido discutidas em um congresso partidário. O último congresso partidário não mudou dessa forma; as últimas decisões da direção nacional, sim; mas é totalmente diferente de um congresso partidário, onde você pactua e diz: olha, eu não quero mais ser assim (HELENA, 2018, em entrevista à autora).

Sobre o porquê de as alas mais à esquerda permanecerem no partido, apesar de estarem sem poder e ignoradas pelo Campo Majoritário, Goldfrank e Wampler (2008) avaliam que, além de não terem para onde ir, o fato de amealharem cerca de $48 \%$ dos votos nas eleições internas garantia sua importância no partido, e por isso o Campo Majoritário não poderia desconsiderá-las em eventual distribuição de cargos no governo federal - o que de fato aconteceu alguns anos depois. Sobre esse grupo, Alencar comenta:

Heloísa, senadora, Babá, Luciana e João Fontes participavam de um grupo que chegou a ter 30 deputados aqui na Câmara no primeiro governo Lula. Nós nos reunimos em 2003, 2004, para contestar caminhos dessa transição não tão silenciosa para o centro, digamos assim, que o PT fez. Na verdade, isso sempre foi tenso, doloroso e difícil (ALENCAR, 2017, em entrevista à autora).

Nessa trajetória, o PT - ou ao menos parte da legenda - abandonou o perfil marcantemente externally mobilized e policy-seeking e adquiriu características de um partido vote-seeking, como forma de ganhar as eleições. O PT resolveu adaptar-se às regras do jogo eleitoral com vistas a atingir seus objetivos, mas a mudança não fora assimilada pela legenda como um todo. A

Caderno Eletrônico de Ciências Sociais, Vitória, v. 8, n. 1, pp. 108-135, 2020. 
ala mais à esquerda manteve as características originais e isso marcaria o partido que chegou ao Palácio do Planalto.

A diferença de visões entre Heloísa Helena e Nelson Pellegrino sobre a Carta ao Povo Brasileiro ${ }^{10}$, deixa clara a divergência existente entre esses dois grupos. Para a ex-senadora, tratava-se de uma "carta aos banqueiros [...] que já sinalizava a mudança" (HELENA, 2018, em entrevista à autora). Já para Pellegrino, o documento foi uma das concessões feitas por Lula, na busca dos $21 \%$ de votos que Ihe faltavam para ganhar as eleições.

Hunter (2007) destaca que a queda na rejeição do PT e de seu líder reflete o desenvolvimento de uma imagem menos sectária. A taxa de rejeição a Lula, que superava $40 \%$ em 1989, e que caíra para 32\% em 1994 e $27 \%$ em 1998 , variava entre $10 \%$ e $16 \%$ em 2002 . Ao mesmo tempo, os simpatizantes de Lula deixavam de concentrar-se entre brasileiros do sexo masculino, de maior nível educacional e na classe média. Lula conquistava a simpatia de ocupantes de classes sociais mais baixas, de regiões mais pobres, de baixo nível educacional, idosos, mulheres e os que se enquadravam em um espectro ideológico mais amplo.

O PT se desenvolveu ao ponto de encontrar o difícil, porém, crucial equilíbrio entre assimilar o ambiente político e conservar uma identidade alternativa, normalmente um desafio para os primeiros partidos ideológicos que buscavam ampliar sua base de apoio (HUNTER, 2007, p.465 - tradução nossa).

A terceira fase do PT tem início com a chegada de Lula ao Planalto, tendo como vice-presidente José Alencar, grande empresário do ramo têxtil de Minas Gerais - segundo maior estado em número de eleitores - e integrante do PL partido de direita que reunia também ruralistas e evangélicos, grupos que historicamente votavam contra o PT. A chapa formada por Lula era rejeitada pelas alas mais à esquerda do partido. "Eu me lembro, me recordo muito, da pressão da base, nas convenções e encontros, a multidão de filiados participando de congressos do PT, de convenções eleitorais, bradando: PL não! Aliança com o povão!" (ALENCAR, 2017, em entrevista à autora).

Ao chegar ao Planalto, Lula se deparou com uma base de apoio minoritária no Parlamento, realidade idêntica à vivenciada por todos os presidentes que o antecederam no período pós-1988, o que significava a necessidade de formar uma base de apoio que viabilizasse a governabilidade. A decisão por não incluir o PMDB - segunda maior bancada da Câmara dos

10 Lido pelo então candidato Lula em 22 de junho de 2002, durante encontro no PT sobre o programa de governo, o documento apresentava críticas à gestão de Fernando Henrique Cardoso, sobretudo à sua política econômica, e apresentava diretrizes sob as quais se daria a mudança, caso Lula fosse eleito.

Caderno Eletrônico de Ciências Sociais, Vitória, v. 8, n. 1, pp. 108-135, 2020. 
Deputados - em sua coalizão levou o presidente a formar uma base de elevado grau de heterogeneidade ideológica, que reunia do PCdoB (parceiro histórico do PT) ao PL (do vice-presidente).

Não bastassem as esperadas dificuldades em administrar uma base com tais características, Lula se defrontou com outro problema: as divisões internas do seu partido. As facções à esquerda, que permaneceram contidas entre 1995 e 2002, viam na chegada ao governo a possibilidade de implantar as políticas públicas por elas sempre defendidas. Além disso, criticavam a política fiscal restritiva adotada por Lula e posicionavam-se contra a divisão do gabinete com os demais partidos. "Quantas e quantas vezes reunimos com o presidente Lula, com a bancada, com o ministro (da Fazenda, Antonio) Palocci, com a bancada para ele explicar o projeto" (PELLEGRINO, 2018, em entrevista à autora). O parlamentar destaca ainda os reflexos das crises na bancada por ele liderada nos demais partidos da base. "Toda vez que alguém do PT declarava que não ia votar na Reforma da Previdência, os aliados usavam esse argumento: se o PT, que é o partido do presidente, não vota, a gente não vai votar também" (PELLEGRINO, 2018, em entrevista à autora).

Durante a tramitação da proposta de reforma da Previdência apresentada por Lula em 2003, três deputados federais (Luciana Genro, Babá e João Fontes) e uma senadora (Heloísa Helena) foram expulsos do PT por votarem contra a reforma e acusarem as lideranças partidárias de traírem bandeiras históricas da legenda. "A opção pela punição foi [...] um claro recado às facções mais radicais de que a independência parlamentar não seria tolerada" (AMARAL, 2010, p. 120). Suplicy explicita isso quando relata que José Dirceu, em reunião com a bancada do partido, deixou bem claro ao senador que, se este fosse defender Heloísa Helena, tornar-se-ia "um inimigo, um adversário dele" (SUPLICY, 2018, em entrevista à autora). Alencar assim comenta as consequências sofridas por sete deputados que decidiram abster-se na votação da Reforma da Previdência. "O Genoíno, presidente do partido, nos tirou de todas as relatorias, de todas as presidências de comissão, ficamos quase que à margem da bancada" (ALENCAR, 2017, em entrevista à autora).

Apesar das medidas adotadas ao final de 2003, a esquerda do partido ocupava cerca de $30 \%$ das cadeiras do PT na Câmara dos Deputados, possuía estreita relação com os movimentos sociais e o governo sempre soube que não poderia ignorá-la. A solução encontrada por Lula foi ampliar o número de ministérios e secretarias com status ministerial e distribuí-los entre representantes desse grupo. A desproporcional presença do PT nos cargos de primeiro e de segundo escalão, no entanto, dificultou a consolidação do apoio dos demais partidos da base. 
Todavia, as medidas adotadas não foram suficientes para aplacar a frustração da esquerda partidária com os rumos do partido e do governo. Militantes descontentes se reuniram aos parlamentares expulsos do PT e fundaram, em 2004, o Partido Socialismo e Liberdade (PSOL).

\section{Sobre a formação e a gestão da base do Governo}

Dois pontos chamam especial atenção na forma como o governo Lula montou e geriu sua coalizão: a concentração dos cargos ministeriais e de segundo escalão em seu partido e a priorização do pagamento de emendas orçamentárias de parlamentares que não integravam sua base de apoio, inclusive integrantes de partidos da oposição.

Ainda em 2002, Lula já eleito, debatia-se o ingresso do PMDB na coalizão de governo. Segundo Alencar, o PT não sabia se seria possível governar "pressionando o Parlamento em torno de projetos e propostas do governo para que elas fossem aprovadas ou pela institucionalidade mais tradicional, criando uma coalizão que fideliza apoio ao governo" (ALENCAR, 2017, em entrevista à autora), o que incluiria buscar o PMDB, tradicionalmente presente em todos os governos, ou substituí-lo por um conjunto de siglas menores.

E como o PT é muito hegemonista, não teria a sombra do PMDB, o segundo partido com bancada aqui. Então, um pouco 'dividir para reinar'. E aí começou o procedimento de conquista desses partidos menores, inclusive aqueles que eram, dentro da concepção do PT, visceralmente distantes com nenhuma proximidade ideológica e programática (ALENCAR, 2017, em entrevista à autora).

Entretanto, já em 2004, o PMDB passou a integrar formalmente a base de apoio de Lula. Ocorre que, apesar de representar $24,53 \%$ desta, somente foi contemplado com dois ministérios - mesma quantidade do PCdoB, partido historicamente parceiro do PT e que participava com 2,83\% da coalizão. Isso ajuda a explicar o fato de, menos de um ano após sua adesão à base, o PMDB decidir por abandoná-la, o que efetivamente não aconteceu por haverem seus ministros optado por permanecer no governo.

A opção de Lula de formar a coalizão com o maior número de partidos e mais ideologicamente heterogênea de que se tem conhecimento até então resultou na esperada dificuldade de geri-la. Segundo Pellegrino, os primeiros quatro anos do governo foram marcados pela fragilidade de sua base, integrada por partidos que eram mais amigos do governo do que do projeto, com o qual não tinham identidade ideológica.

Eu sempre brincava que não me interessava que o PMDB estivesse no governo; me interessava que o PMDB estava votando nas nossas

Caderno Eletrônico de Ciências Sociais, Vitória, v. 8, n. 1, pp. 108-135, 2020. 
políticas; e o PMDB nunca se preocupou muito com projeto estratégico nosso; o que o PMDB queria saber era qual o cargo que ele ia ter no governo, para que aqueles cargos pudessem ser base para a sustentação dos seus projetos (PELLEGRINO, 2018, em entrevista à autora).

A decisão do governo de concentração de cargos em seu partido é entendida de forma diferente pelos parlamentares entrevistados. Alencar e Pellegrino deixam claro ser da cultura do partido a desconfiança em relação aos integrantes das demais legendas. Alencar menciona, inclusive ser essa a mais singular característica do PT, exatamente pela pressão da sua base. "Olha, o departamento tal está com o Fulano, quem indicou foi o próprio Roberto Jefferson, por exemplo, mas, ali em baixo, para controlá-lo, vai estar o Fulano, o companheiro Beltrano" (ALENCAR, 2017, em entrevista à autora). Pellegrino, por sua vez, revela a preocupação de "sempre botar alguém para fazer a marcação" (PELLEGRINO, 2018, em entrevista à autora). Ele reconhece que os aliados reclamavam da prática, mas nega tratar-se de recusa a distribuir o poder; segundo o parlamentar, o governo "queria salvaguardas não só no plano da política, mas como também no plano até da moralidade pública também" (PELLEGRINO, 2018, em entrevista à autora).

Suplicy, todavia, entende como natural a forte presença do PT no comando do governo, dada a elevada aceitação do presidente pela opinião pública. Já para Ananias, formou-se "uma geração no PT de altíssima competência [...] o modo petista de governar" (ANANIAS, 2018, em entrevista à autora). Soma-se a isso, segundo ele, que nem todos os que integravam o governo estavam interessados em viabilizar políticas públicas, em dar uma contribuição efetiva ao país.

Pode-se dizer que seria considerado natural que, ao chegar ao poder, o PT houvesse crescido, dado o caráter centrípeto característico do presidente da República - a chamada fase de lua de mel, conforme Abranches (2018), sobretudo se considerada a popularidade de Lula, uma vez que, até 2007, não havia limitações à troca de partidos. Mas não foi o que aconteceu. O PT ganhou somente dois deputados, ao passo que dezenas de outros migraram para outros partidos da base - o porquê foi revelado pela CPMI.

Mais uma vez a história do PT ajuda a entender esse fenômeno. Segundo Alencar, "o PT tem - ou tinha, pelo menos - critérios mais rígidos, não aceitava qualquer um, tinha que ir a debate, tinha que sabatinar, mas não. Ele foi inchando, com as benesses que um governo pode dar, partidos dessa base, tirando de uns, botando em outros" (ALENCAR, 2017, em entrevista à autora). Na mesma linha, afirma Pellegrino: "Nós não trouxemos ninguém para o PT que não tivesse identidade com o partido. [...] por que que não chegamos a 130

Caderno Eletrônico de Ciências Sociais, Vitória, v. 8, n. 1, pp. 108-135, 2020. 
deputados? Porque não interessava trazer para o PT quem não tivesse identidade com o partido" (PELLEGRINO, 2018, em entrevista à autora).

\section{O PT (ou os PTs) chega (ou chegam) ao Planalto}

O Partido dos Trabalhadores que chegou ao Planalto em 2003 era um partido dividido. É certo que o PT sempre foi uma legenda com múltiplas tendências e consequentemente conflitos, como reflexo de sua origem externally mobilized. Mas, desta feita, a divisão era outra. O PT se dividia basicamente em dois grandes grupos: aquele sob o comando do Campo Majoritário - resultante da união das facções consideradas de centro e de direita e personificado em Lula e José Dirceu - e o que reunia aqueles que, em maior ou menor grau, eram da chamada esquerda do partido. Sob a ótica da organização dos partidos, o PT se dividia, respectivamente, entre uma parcela vote-seeking e outra, policy-seeking.

O perfil vote-seeking se delineou a partir da adoção de uma série de práticas inicialmente rejeitadas pela legenda: financiamento empresarial de campanha; ênfase na ocupação de cargos nas esferas executivas em detrimento do crescimento parlamentar; coligações com partidos que não eram de esquerda, até então considerados corruptos, personalistas, centristas ou clientelistas - como o PL de José Alencar -, eventualmente com a cessão da cabeça de chapa; e reconstrução da imagem de seu principal líder, que passou a ser conhecido como "Lula, paz e amor". Mudanças como essas permitiram ao PT ampliar seu eleitorado; o PT adaptou-se para jogar o jogo de um sistema eleitoral caro, multipartidário e fragmentado como o brasileiro - e venceu.

Por sua vez, a chamada esquerda partidária, que mantinha características policy-seeking, passou a defender bandeiras que the eram caras e a rejeitar propostas e políticas públicas consideradas de direita. Já no primeiro ano, o choque entre os dois grupos ficou patente.

O PT que chegou ao governo era um partido híbrido comandado pela parcela vote-seeking, mas que não poderia ignorar que a fração policy-seeking era importante tanto no Parlamento, quanto junto à militância do partido, aos movimentos sociais e, consequentemente, para a imagem do partido. Administrar essas tensões foi, sem dúvida, mais um desafio para Lula, cuja base de apoio já era, por si só, dadas suas características, de difícil condução.

Lula ampliou o número de cargos com status ministerial e, na tentativa de atender aos integrantes do seu partido, destinou-lhes os que se relacionavam a políticas públicas identificadas como bandeiras históricas da legenda. A estratégia, voltada para a redução das tensões intrapartidárias, resultou todavia na redução do espaço de outros partidos da base de apoio do governo, que teriam de ser cooptados de outra forma.

Caderno Eletrônico de Ciências Sociais, Vitória, v. 8, n. 1, pp. 108-135, 2020. 
O escândalo do Mensalão ampliou esse leque de divergências. Integrantes do partido mais ligados ao governo negaram a prática ou a associaram ao "caixa dois" - e assim seguem fazendo até hoje. Já uma outra parcela da legenda, mesmo sem reconhecer explicitamente a prática, defendeu uma refundação; a realização de uma autocrítica - o que foi tentado na eleição do presidente do partido, em 2005. No entanto, a eleição de Ricardo Berzoini (da chapa Construindo um Novo Brasil, herdeira do Campo Majoritário) ampliou ainda mais a divergência entre os dois grupos. Integrantes da esquerda do partido que ainda se mantinham na legenda - como os deputados federais Chico Alencar, Ivan Valente e Maninha - filiaram-se ao PSOL ainda nesse ano.

As entrevistas realizadas permitem perceber como representantes dos dois grupos enxergam o processo de mudanças sofrido pelo PT, as coligações, a aceitação de financiamento empresarial de campanha e a própria existência do Mensalão. Helena critica o fato de as mudanças na legenda não haverem sido confirmadas em um congresso partidário, como era da tradição do PT. Alencar fala em uma transição não explicitada e debatida e dá como exemplo a rejeição dos militantes à aliança com o PL. Segundo ele, a esquerda classificava o financiamento empresarial como um casamento com a burguesia, as classes dominantes, os dirigentes. Pellegrino e Ananias, por sua vez, se por um lado reconhecem que a aceitação do financiamento empresarial de campanha e a aliança com partidos de centro-direita impactaram negativamente o partido, recorrem à história do Brasil e suas práticas paternalistas como forma de justificá-las.

Alguns estudiosos do tema afirmam que o Mensalão teria começado após a dificuldade do governo de aprovar a Reforma da Previdência e ao fracasso na tentativa de realização de ampla Reforma Tributária, ambas ao final de 2003 ou seja, após a governabilidade apresentar-se ameaçada. Mas não é o que apontam os diagramas da CPMI dos Correios, os quais revelam repasses do chamado Valerioduto para políticos e partidos integrantes da base de apoio do governo Lula já no início de 2003. Ou seja, o Mensalão não surgiu para minimizar insucessos na gestão. A prática foi adotada desde o primeiro momento, o que confirma sua adoção como integrante da chamada presidential toolbox, substituindo, ao menos em parte, as ferramentas tradicionalmente empregadas.

Ao chegar ao Planalto, o Partido dos Trabalhadores, ou ao menos a parcela que liderava o governo, retomou crenças e práticas antigas, como não confiar nos parceiros, o que fica evidente nas falas de Alencar e Pellegrino, de que, nos ministérios entregues a outras legendas, havia sempre alguém do PT para vigiar. Ou ainda na alegada competência de seus militantes, além do "modo petista de governar" exaltado por Ananias ou na natural expectativa,

Caderno Eletrônico de Ciências Sociais, Vitória, v. 8, n. 1, pp. 108-135, 2020. 
segundo Suplicy, de que o PT prevalecesse no comando, dada a elevada aceitação de Lula pela opinião pública. Para Helena, a distribuição de cargos para militantes do partido tinha por objetivo comprar e, consequentemente, calar os movimentos sociais. Cardoso (2016) parece ter antevisto a prática ainda em 1988, quando, após conversar com Lula, registrou na gravação que fizera naquele dia, o fundamentalismo do PT e a tendência de o partido buscar o monopólio do poder por não aceitar alianças.

Ao que tudo indica, apesar de todas as mudanças, permanecia no PT que chegou ao poder a ideia de existência de 300 picaretas no Congresso Nacional, como dissera Lula, em $1993^{11}$. Para SERRAGLIO (2017, em entrevista à autora), "o melhor mecanismo era comprar os picaretas; melhor do que ficar negociando com eles um por um". Também em entrevista à autora, Teixeira (2018) ressalta que, em 2003, quando foi ministro, o caráter burguês do Parlamento era muitas vezes ressaltado, havendo o entendimento de que, por isso, tudo se resolveria com o Orçamento. Segundo ele, quando a base do governo atingiu 318 deputados, estes eram cooptados com o Orçamento, com administração de recursos, "dinheiro para o bolso das pessoas". Ananias, por sua vez, menciona a dificuldade de lidar com a burguesia brasileira, por ele considerada apátrida e mal-acostumada.

Lula, todavia, não poderia prescindir de construir uma supermaioria no Parlamento. Seria natural que o PT houvesse crescido pela incorporação de parlamentares de outros partidos, mas somente foram registrados dois ingressos na legenda. Em contrapartida, a CPMI dos Correios identificou dezenas de transferências de parlamentares para os demais partidos da base diretamente correlacionadas com o Mensalão. Mais uma vez a história do PT explica o fenômeno. Alencar lembra que o PT não aceitava qualquer um, havia debate, sabatina. Pellegrino disse que a legenda poderia ter saltado de 94 para 130 deputados, mas que não Ihes interessava quem não fosse ideologicamente identificado. Ou seja, diante da necessidade de ampliar sua base de apoio, o governo preferiu manter os critérios originais do PT relativos à filiação partidária e remunerar os demais partidos para que estes crescessem.

\section{Conclusão}

Sob a ótica do Institucionalismo Histórico, foi possível concluir que, em que pese ao conjunto de mudanças realizadas pela legenda entre 1995 e 2002, com vistas à eleição de seu principal líder, seguiam fortes no PT princípios

\footnotetext{
${ }^{11}$ Quando presidente do PT, Lula afirmou: "De todos os deputados do Congresso Nacional, há pelo menos 300 picaretas. E eles foram eleitos, não caíram lá de paraquedas. São políticos que põem seus interesses acima de suas obrigações com a comunidade" (SILVA, 1993).
}

Caderno Eletrônico de Ciências Sociais, Vitória, v. 8, n. 1, pp. 108-135, 2020. 
fundamentais características de sua origem externally mobilized e policyseeking, características essas que se refletiram na estratégia adotada na formação e gestão da coalizão de apoio do primeiro governo Lula. A legenda que passara por profundas mudanças e jogou o jogo eleitoral brasileiro para eleger seu principal líder ainda guardava, de forma significativa, valores originários: via o Parlamento como uma instituição burguesa e integrada por picaretas; resistia a alianças; desconfiava dos parceiros a ponto de vigiá-los; insistia em manter-se hegemônica; e não queria macular seu nome, incorporando integrantes cuja trajetória política divergia da sua. Essa trajetória bem se aproxima do que essa vertente do Institucionalismo apresenta como path dependency.

Ao decidir pela realização de mudanças, o PT já conhecia o sistema eleitoral vigente, as regras e o comportamento dos principais atores que nele interagiam, pois tentara chegar ao Planalto em 1989 e 1994. Sob a ótica da Escolha Racional, conclui-se que as mudanças realizadas pelo Partido dos Trabalhadores entre 1995 e 2002 buscavam reduzir as incertezas e basearamse em um típico cálculo estratégico cujo sucesso pode ser aferido não somente pela eleição de Lula, mas também pela queda na taxa de rejeição deste de $32 \%$ em 1994, para $27 \%$ em 1998 e algo entre $10 \%$ e $16 \%$ quando eleito presidente, em 2002.

O PT, sem dúvida, enfrentou riscos quando decidiu abandonar valores que Ihe eram caros e preocupar-se "cada vez menos em defender os interesses dos trabalhadores e cada vez mais em expandir sua ocupação nos cargos públicos" (VIEIRA, 2012, p. 29) - ou, como afirmou Alencar, abandonar o seu "éthos revolucionário" e associar-se ao $\mathrm{PL}$, apesar dos protestos da militância. Mas, em contrapartida, os eleitores de Lula expandiram-se. Aos brasileiros do sexo masculino, de maior nível educacional e ocupantes da classe média, agregaramse ocupantes de classes sociais mais baixas, de regiões mais pobres, de baixo nível educacional, idosos, mulheres e os que se enquadravam em um espectro ideológico mais amplo - o PT assumia características do tipo catch-all. ${ }^{12}$

\footnotetext{
12 O conceito de partido catch-all foi desenvolvido por Otto Kirchheimer. Conforme explica Amaral (2013), "segundo o autor a combinação entre crescimento econômico e amadurecimento do Estado de Bem-Estar provocou uma redução na polarização social e política, diminuindo a importância tanto da ideologia quanto das distinções de classe na cena partidária. Acompanhando as mudanças sociais mais amplas na Europa Ocidental, os partidos de massa estavam gradualmente transformando-se em agremiações diluídas, com apelos genéricos a todos os grupos sociais e cada vez mais voltadas para o sucesso eleitoral" (AMARAL, 2013, p.15). Os partidos de tipo catch-all reúnem as seguintes características: "desideologização" do discurso partidário; fortalecimento da liderança; declínio da importância da militância de base; apelo eleitoral pluriclassista; e abertura para grupos de interesse variados.
}

Caderno Eletrônico de Ciências Sociais, Vitória, v. 8, n. 1, pp. 108-135, 2020. 
Todavia, se por um lado as mudanças realizadas pelo PT foram bemsucedidas no campo eleitoral, por outro, a maneira top-down como foram conduzidas e não bottom-up, como seria da tradição da legenda, implicou profunda cisão do partido, cisão essa que potencializou os desafios já esperados da gestão de uma coalizão altamente fragmentada e de amplo espectro ideológico. Pode-se dizer que, neste ponto, o emprego das duas teorias encontra pontos de tangência, como tem sido defendido pelos chamados border crossers, que, segundo Thelen (1999), resistem a isolar as escolas neoinstitucionalistas.

O PT é uma legenda singular na história política brasileira, quer pela forma como foi fundado, os diferentes grupos que o constituíram, ou por seus princípios originais. Talvez, por isso, a forma como se deram as mudanças que viabilizaram o sucesso eleitoral obtido em 2002 marcou tão fortemente a legenda. $O$ partido que passara por profundas mudanças e adotara práticas comuns às demais legendas para jogar o jogo eleitoral não se portou da mesma forma ao chegar à Presidência da República. Havia aprendido a jogar o jogo eleitoral, mas não quis, ou não conseguiu, jogar o jogo da governabilidade com as ferramentas existentes. Para conseguir governar, mas seguir hegemônico e manter a imagem construída em suas origens, incorporou o Mensalão à caixa de ferramentas de gestão da coalizão (presidential toolbox).

A pesquisa que serviu como base para este artigo foi desenvolvida como Estudo de Caso, que permite a utilização, entre outras, de duas fontes de pesquisa: análise documental e realização de entrevistas - ambas empregadas no estudo realizado.

O trabalho analisou o porquê de, ao montar e gerir sua base de apoio no Congresso Nacional, Luiz Inácio Lula da Silva haver substituído, ao menos em parte, as tradicionais ferramentas de gestão da coalizão presidencial pela compra de parlamentares e de partidos políticos, o que ficou conhecido como Mensalão. As bases teóricas utilizadas foram o Institucionalismo Histórico e a Teoria da Escolha Racional. Convém dizer que o emprego do Institucionalismo Histórico na análise das mudanças realizadas pelo PT ao longo de sua história, e que resultaram no Mensalão, já acontece no trabalho de Wendy Hunter. A pesquisa realizada buscou agregar a esta linha de estudo as entrevistas realizadas com atores políticos historicamente ligados ao PT. Da mesma forma, não somente com as entrevistas, mas sobretudo com a análise documental da Ação Penal 470 e de documentos da CPMI dos Correios, o estudo reforça o entendimento já presente no trabalho de Pereira, Power e Raile (2009), de que o Mensalão integrou, de fato, a chamada presidential toolbox.

Caderno Eletrônico de Ciências Sociais, Vitória, v. 8, n. 1, pp. 108-135, 2020. 


\section{Referências}

ABRANCHES, Sérgio. 2018. Os Ciclos do Presidencialismo de Coalizão. Disponível em: https://www.academia.edu/6411308/Os_Ciclos_do_Presidencialismo_de_Co aliz\%C3\%A3o. Acesso em 11.12.2018.

AMARAL, Oswaldo E. do. 2010. Adaptação e resistência: PT no Governo Lula entre 2003 e 2008. Revista Brasileira de Ciência Política, Brasília, n. 4, pp. 105-143.

AMARAL, Oswaldo E. do. 2013. O que sabemos sobre a organização dos partidos políticos: uma avaliação de 100 anos de literatura. Revista Debates, Porto Alegre, v.7, n. 2, pp. 11-32.

CARDOSO, Fernando H. 2016. Diários da Presidência, 1997-1998. São Paulo: Companhia das Letras,

FIGUEIREDO, Argelina C., LIMONGI, Fernando. 2007. Instituições políticas e governabilidade: desempenho do governo e apoio legislativo na democracia brasileira. In: RANULFO, Carlos M., SAEZ, Manuel. A democracia brasileira: balanço e perspectivas para o Século XXI, Belo Horizonte: Editora UFMG, pp. 25-32..

GOLDFRANK, Benjamin, WAMPLER, Brian. 2008. From petista way to Brazilian way: how the PT changes in the road. Revista Debates, Porto Alegre, v. 2, n. 2, pp. 245-271.

HALL, Peter A.; TAYLOR, Rosemary C. R. 2003. As três versões do neoinstitucionalismo. Lua Nova, São Paulo, n. 58, pp. 193-223.

HUNTER, Wendy. 2007. The normalization of an anomaly: the Workers' Party in Brazil. World Politics, Cambridge, v. 59, n. 3, pp. 440-475.

HUNTER, Wendy. 2010. The transformation of the Workers' Party in Brazil, 1989-Cambridge: University Press.

MARTINS, José de S. 2016. Do PT das lutas sociais ao PT do poder. São Paulo: Contexto.

MELO, Marcus A., PEREIRA, Carlos. 2013. Making Brazil work: checking the president in a multiparty system. New York: Palgrave Macmillan.

PEREIRA, Carlos, POWER, Timothy, RAILE, Eric. 2009. Presidencialismo de coalizão e recompensas paralelas: explicando o escândalo do mensalão. In: INÁCIO, Magna; RENNÓ, Lucio. Legislativo brasileiro em perspectiva comparada. Belo Horizonte: Editora UFMG, pp. 207-233. 
POWER, Timothy J. 2011. O presidencialismo de coalizão na visão dos parlamentares brasileiros. In: POWER, Timothy J.; ZUCCO Jr, Cesar (Orgs.). $O$ congresso por ele mesmo: autopercepções da classe política brasileira. Belo Horizonte: Editora UFMG, pp.131-163.

RAILE, Eric D.; PEREIRA, Carlos; POWER, Timothy J. 2011. The executive toolbox: building legislative support in a multiparty presidential regime. Political Research Quarterly, Salt Lake City, v. 64, n. 2, pp. 323-334.

RAILE, Eric D.; PEREIRA, Carlos; POWER, Timothy J. 2006.The Presidential Toolbox: generating support in a multiparty presidential regime. Disponível em:

http://citation.allacademic.com/meta/p_mla_apa_research_citation/1/5/2/7 /4/pages152749/p152749-1.php. Acesso em: 23.10.2017.

SANT'ANA, Maristela M. 2018. Mensalão como ferramenta de gestão da coalizão no primeiro Governo Lula. Brasília (DF). Dissertação (mestrado, Ciência Política). Câmara dos Deputados, Centro de Formação Treinamento e Aperfeiçoamento (Cefor),. Disponível em: <http://bd.camara.leg.br/bd/handle/bdcamara/36706>Acesso em: 23.10.2020.

SECCO, Lincoln. 2011. História do PT 1978-2010. Cotia: Ateliê Editorial.

SENADO FEDERAL. 2006. Comissão Parlamentar Mista de Inquérito - CorreiosRelatório Final. Disponível em: http://www.senado.gov.br/atividade/Comissoes/CPI/RelatorioFinalCorreios.a sp. Acesso em 21.09.2017.

SILVA, Luiz I. L. da. Acervo $O$ Globo, 1993. Disponível em: http://acervo.oglobo.globo.com/incoming/de-todos-os-deputados-docongresso-nacional-hapelo-menos-300-picaretas-eles-foram-eleitos-naocairam-la-de-paraquedas-sao-politicos-quepoem-seus-interesses-acima-desuas-obrigacoes-com-comunidade-21325088\#ixzz53h8pH2zH. Acesso em 09.01.2018.

THELEN, Kathlen. 1999. Historical Institutionalism in Comparative Politics. Annual Review of Political Science, California, v.2, pp. 369-404.

VIEIRA, Rafaela. 2012. O transformismo petista: considerações acerca das transformações históricas do Partido dos Trabalhadores no Brasil. Memorias: revista digital de História y Arqueologia desde El Caribe Colombiano, Barranquilla, ano 9, n. 17, pp. 01-58. 